Case report

\title{
Bone metastasis of malignant pheochromocytoma four years after adrenalectomy
}

\author{
Vitorino Modesto dos Santos ${ }^{1,2}$, Marcos Correa da Trindade ${ }^{2}$, Renata Faria Silva ${ }^{2}$, Uadson Silva Barreto ${ }^{2}$ \\ ${ }^{1}$ Catholic University Medical Course, Brasília-DF, Brazil \\ ${ }^{2}$ Armed Forces Hospital, Brasília-DF, Brazil
}

Received 25 November 2015, Revised 21 January 2016, Accepted 22 January 2016

(C) 2015, Santos V.M., Trindade M.C., Silva R.F., Barreto U.S.

(C) 2015, Russian Open Medical Journal

Abstract: Malignant adrenal pheochromocytoma is an uncommon entity with low 5-year survival rate. Early diagnosis and adrenalectomy often yields good clinical outcome. The aim of the present case study is to report a 64-year-old Brazilian man with bone metastases of malignant pheochromocytoma first diagnosed and treated by right adrenalectomy four years ago. Recent evidence emphasized the recommendation about the safest duration of follow up, which should be at least 10 years from the first operation or first diagnosis of adrenal pheochromocytoma.

Keywords: adrenal gland, bone metastasis, malignant pheochromocytoma

Cite as Santos VM, Trindade MC, Silva RF, Barreto US. Bone metastasis of malignant pheochromocytoma four years after adrenalectomy. Russian Open Medical Journal 2016; 5: e0207.

Correspondence to Prof. Vitorino Modesto dos Santos. Address: Armed Forces Hospital, Estrada do Contorno do Bosque s/n, Cruzeiro Novo, 70658-900, Brasília-DF, Brazil. Phone: \#55-61 39662103. Fax: \#55-61 32331599. E-mail: vitorinomodesto@gmail.com.

\section{Introduction}

Adrenal masses are common conditions, which very often may be incidentally detected during evaluations for non adrenal disorders [1-3]. The growing frequency of incidentalomas has been up to $4 \%$, and these masses are of benign nature in around $80 \%$ of the individuals [1]. Pheochromocytoma (PCC) represents between 1.5 and $14 \%$ of incidentalomas [5]. The rate of malignant or functional adrenal tumors is low, and for PCC is nearly $2 \%$ [1]. Approximately $10 \%$ of PCC is malignant, with 5 -year survival rate is up to $75.4 \%$, and early diagnosis yield better outcome $[2,4]$. Malignancy rate of adrenal PCC is up to $25 \%$, and the main sites of metastasis are bones, lungs, liver, and lymph nodes [2]. Poor survival of patients with malignant PCC has been directly associated with older age and the presence of synchronous metastases [3]. Surgical resection usually yields good results [2]; nevertheless, the Brazilian male herein reported developed multiple bone metastases four years after adrenalectomy. Choi et al. recently reported lung metastases of malignant PCC diagnosed eleven years after the right adrenalectomy. These recent findings emphasize that duration of the follow up periods should be at least 10 years from the first operation or first diagnosis of PCC [2]. Indeed, one must ever take in account the hypotheses either of recurrence of PCC or metachronous development of tumor in chromaffin site [2].

\section{Case report}

A 64-year-old male with arterial hypertension and type 2 diabetes was admitted because of palpitations, breathlessness and obstructive sleep apnea controlled by continuous positive airway pressure (CPAP). The first suspicion of PCC was established during a routine urological evaluation done four years before. The tumor was incidentally detected by computed tomography (CT) images of abdomen as a heterogeneous hypodense mass $(7.6 \times 7.0 \times 6.6 \mathrm{~cm})$ on the right adrenal gland, presenting areas with cystic degeneration, necrosis, and focuses of calcification, with contrast enhancement. The adrenal mass shifted the right kidney downward and backward (Figures 1a to 1c). Elevated levels of urinary 5-hydroxi-indolacetic acid, metanephrines and normetanephrines, and tumor specimens showing pleomorphic cells with anastomosing trabecular pattern and bizarre nuclei, in addition to the consistent immunohistochemistry findings (Figures $1 \mathrm{~d}$ to $1 \mathrm{f}$ ) confirmed the initial clinical hypothesis of an adrenal PCC. The immunohistochemistry panel, with respective clones and results included: synaptophysin (27G12) positive; chromogranin (LK2H10) positive; vimentin (V9) positive; Ki-67 (SP6) 1\%-5\% positive; S-100 protein positive in sustentacular cells; additionally to inhibin- $\alpha$ (R1) negative; calretinin (DAK Calret 1) negative; melan-A (A103) negative; and pan-cytokeratin (AE1/AE3) negative. With establishment of the diagnosis the patient underwent right adrenalectomy. Since the early postoperative period, the symptoms improved, with normalization of blood pressure and of glycemic levels. Control of urinary hormone determinations in 24 hours were metanephrines $65.6 \mu \mathrm{g}$ (normal: $\geq 320 \mu \mathrm{g}$ ), normetanephrines $1846 \mu \mathrm{g}$ (normal: $\leq 390 \mu \mathrm{g}$ ), and 5-hydroxiindolacetic acid $3.5 \mathrm{mg}$ (normal: $\leq 9.0 \mathrm{mg}$ ). The patient was further referred to ambulatory follow-up. 

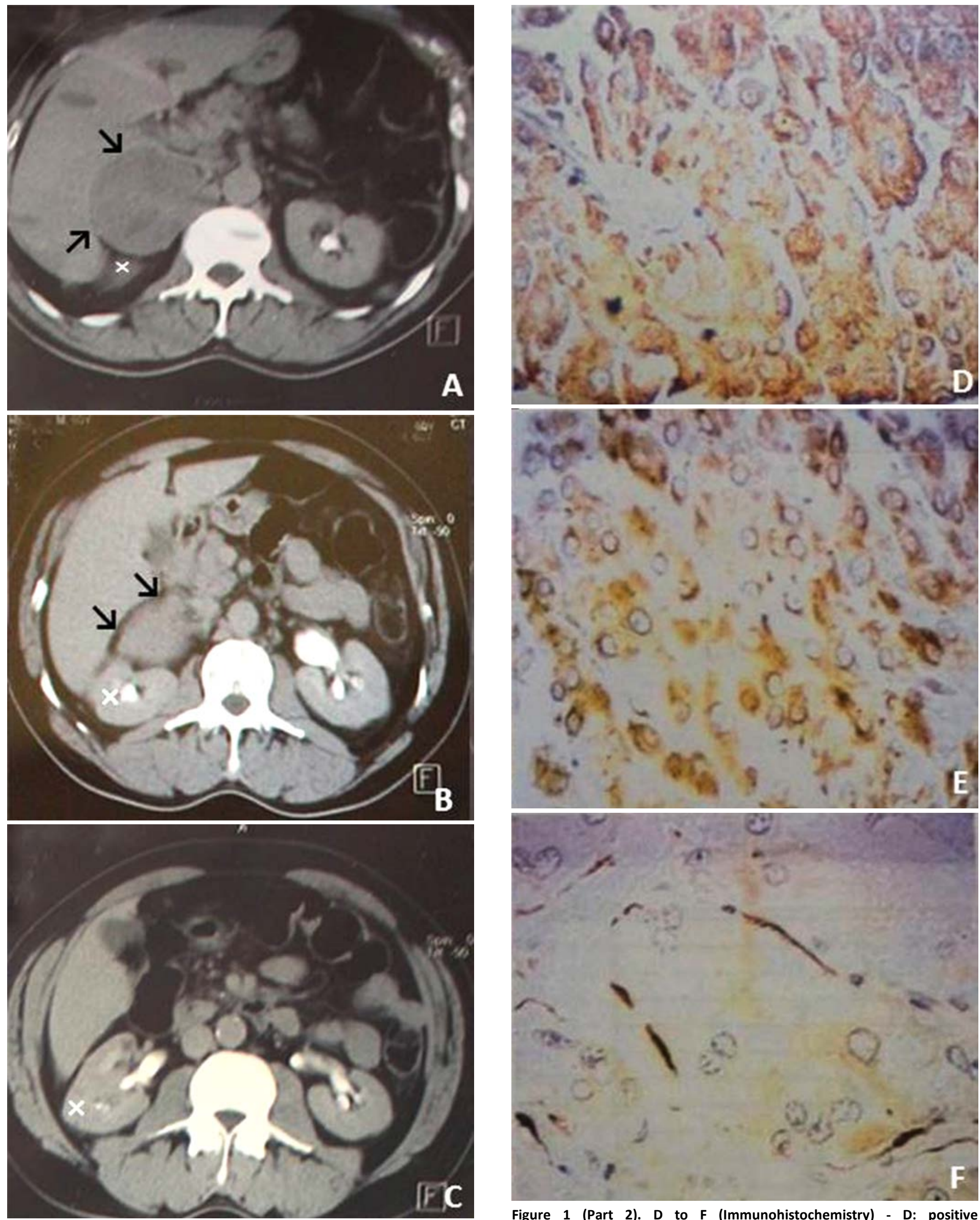

Figure 1 (Part 1). A to C (Computed tomography): images of large heterogeneous hypodense mass on the right adrenal gland (arrows) with cystic areas, shifting the right kidney (astherisks) downward and backward. 


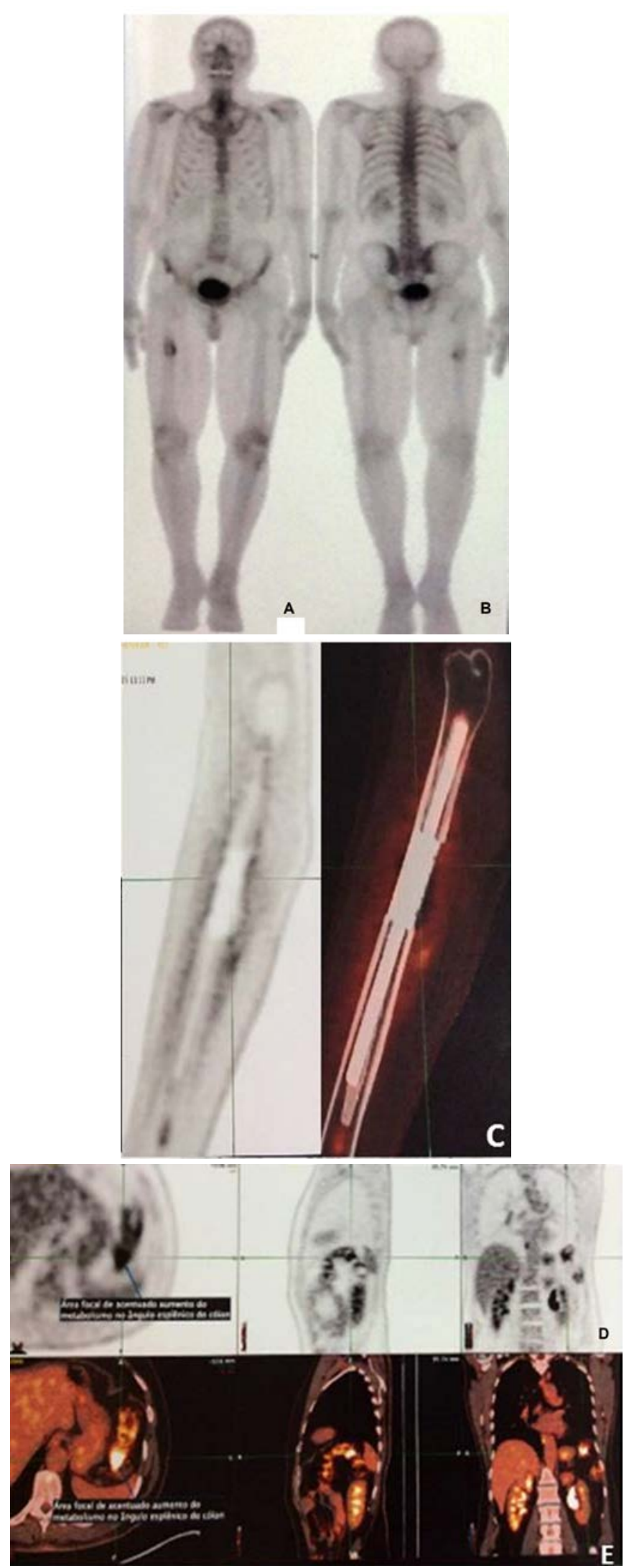

Figure 2. Post adrenalectomy PET/CT showing osteolytic lesions at the the right femoral diaphysis (A-B); right femoral intramedullar prosthesis with enhanced metabolism in the surrounding tissues (C); lesion at third sacral vertebra (D); and focal area on the splenic angle of the colon (E).
Four years later, without any local trauma, he started with continuous pain on the right thigh, in absence of muscle weakness or instability. Radiograph images of the right thigh showed a lesion on the femoral shaft, which affected both the cortical and the periosteal regions. The major hypothesis was about bone metastasis; then, the patient underwent excision of the implant and a femoral prosthesis was utilized. Histopathological evaluation of surgical samples showed undifferentiated malignancy characterized by round cells with aboundant clear or eosinophilic granular cytoplasm; with central ovoid nuclei and coarse pattern of chromatin, and evident nucleoli and scarce mitosis. Immunohistochemistry studies revealed chromogranin with weak cytoplasmic positivity; synaptophysin with strong cytoplasmic positivity: and S-100 protein with moderate cytoplasmic intensity, which is a consistent pattern with bone metastases from malignant pheochromocytoma. Postoperative positron emission tomography-computed tomography (PET/CT) of control revealed osteolytic lesions on the third sacral vertebra; focal area on the splenic angle of the colon; and the right femoral intramedullar prosthesis with enhanced metabolism in the surrounding tissues (Figures 2a to 2e). The patient was referred to the Oncology care and his follow-up has been regularly done. Laboratory determinations of are shown in Table 1.

\section{Discussion}

PCC and paraganglioma are benign or malignant neuroendocrine neoplasms from neural crests, with diverse clinical courses [4-7]. Worthy of note, metastases of the malignant tumors involve lymph nodes, liver, lungs and bones, where chromaffin tissue is normally absent [7]. PCC is located in adrenal glands, whereas paragangliomas develop in paraganglia of the head, neck, thorax, abdomen and pelvis [4-7]. Differences in clinical behaviour and in prognosis, have suggested that these tumors should be considered as separate clinical conditions $[4,5]$. Most frequently, the cases are sporadic, but in up to $25 \%$ they are inherited as familial paragangliomas, and associated with multiple endocrine neoplasia type $2 \mathrm{~A}$ and $2 \mathrm{~B}$, von Hippel-Lindau disease, and von Recklinghausen disease, Carney's triad, and CarneyStratakis syndrome [6, 7]. PCC is called "the $10 \%$ tumor": bilateral, affecting children, genetic, malignant or recurrent, with stroke or multiple endocrine neoplasia (MEN) syndromes, paraganglioma [6].

Firstly, the old patient herein described had incidental finding of adrenal mass in the occasion of a routine urological evaluation and biopsy findings established the diagnosis of PCC. Secondly, the absence of metastasis in imaging evaluations and the lack of indicative features of inherited conditions, led to diagnosis of sporadic case of benign PCC, which was treated by right adrenalectomy without intercurrences. Thirdly, symptomatic bone metastases of malignant PCC were suspected and further confirmed on both femurs, four years after adrenalectomy. The patient underwent excisional surgery for bone metastases, followed by radium therapy $(4,000-5,000 \mathrm{cGy})$ administered in five weeks. Although pertaining to the age group over 60 years, and synchronous or metachronous metastases are wellknown significant prognostic factors of short survival in this adrenal tumor [3, 7], our patient is still alive four years after the establishment of the diagnosis of malignant PCC. Similar phenomenon was reported in a 30-year-old Korean woman with lung metastases eleven years after right adrenalectomy for malignant PCC [2]. 
Table 1. Laboratory data of a 64-year-old man with late metastases of pheocromocytoma

\begin{tabular}{|c|c|c|c|c|c|}
\hline Parameters (normal ranges) & $D 1$ & $D 2$ & D59 & D128 & $D 239$ \\
\hline Hemoglobin (13.5-18.0 g/dL) & 14.2 & 13.3 & 13.6 & 14.9 & 14.6 \\
\hline Hematocrit $(42-52 \%)$ & 42.0 & 37.7 & 41.7 & 45.4 & 44.0 \\
\hline Leukocytes (4-11 x $\left.10^{9} / \mathrm{L}\right)$ & 17.8 & 15.7 & 6.9 & 6.2 & 6.4 \\
\hline Neutrophils (40-70\%) & 91 & 90 & 53 & 82 & 76 \\
\hline Platelets $\left(140-450 \times 10^{9} / \mathrm{L}\right)$ & 241 & 237 & 260 & 229 & 255 \\
\hline PSA $(<5.0 \mathrm{ng} / \mathrm{ml})$ & - & - & 4.87 & 4.86 & 1.91 \\
\hline C-RP (0.5-0.9 mg/dL) & 0.2 & 2.4 & - & - & 0.2 \\
\hline Sodium (135-145 mmol/L) & 140 & 139 & - & - & 140 \\
\hline Potassium (3.5-5.2 mmol/L) & 4.3 & 4.9 & - & - & 4.5 \\
\hline Urea $(10-50 \mathrm{mg} / \mathrm{dL})$ & 29.3 & - & 19.2 & 24.2 & 37.6 \\
\hline Creatinine $(0.7-1.3 \mathrm{mg} / \mathrm{dL})$ & 0.9 & - & 1.1 & 0.9 & 1.1 \\
\hline
\end{tabular}

D, Day of evolution; PSA, prostate-specific antigen; C-RP, C-reactive protein. Abnormal data are showed in bold.

Incidental adrenal masses have been growing in number due to easier accessibility to imaging techniques [1]; therefore, diagnosis challenges involving benign and malignant conditions are also increasing and may create pitfalls in the setting of primary care management. Differential diagnosis of adrenal incidentaloma includes (non-)functioning adenoma, myelolipoma, metastasis, and primary carcinoma [3,5], and constitutes a hard task requiring accurate clinical, laboratory, imaging, and histopathology and immunohistochemistry evaluations $[1,3,5]$. Because of low number of characteristic features on histopathology studies, the early diagnosis of malignant PCC may be hampered [1-3]. Unfortunately, the correct diagnosis of malignancy is sometimes established with base on distant metastasis, as occurred in the present report.

\section{Conclusion}

Early diagnosis and adrenalectomy can yield good outcomes for patients with malignant PCC; however, the safest duration of follow up should be at least 10 years from the first operation or the first diagnosis. Despite of the inherent weakness of a single case study, the present report might enhance the awareness and suspicion index among primary care workers about this rare condition.

Conflict of interest: None to declare.

\section{References}

1. Cho $Y Y$, Suh $S$, Joung $J Y$, Jeong $H$, Je $D$, Yoo $H$, et al. Clinical characteristics and follow-up of Korean patients with adrenal incidentalomas. Korean J Intern Med 2013; 28: 557-564. (doi: 10.3904/kjim.2013.28.5.557)

2. Choi WS, Park JY, Roh MS, Choi PJ. Malignant pheochromocytoma with lung metastasis after right adrenalectomy for pheochromocytoma eleven years ago. J Thorac Dis 2015; 7(3): E37-E42. (doi: 10.3978/j.issn.2072-1439.2015.01.58)

3. Kerkhofs TM, Roumen RM, Demeyere TB, van der Linden AN, Haak HR. Adrenal tumors with unexpected outcome: a review of the literature. Int J Endocrinol 2015; 2015: 710514. (doi: 10.1155/2015/710514)

4. Choi YM, Sung TY, Kim WG, Lee JJ, Ryu JS, Kim TY, et al. Clinical course and prognostic factors in patients with malignant pheochromocytoma and paraganglioma: a single institution experience. J Surg Oncol 2015; 112(8): 815-821. (doi: 10.1002/jso.24063)

5. Ezzat Abdel-Aziz T, Prete F, Conway G, Gaze M, Bomanji J, Bouloux P, et al. Phaeochromocytomas and paragangliomas: a difference in disease behaviour and clinical outcomes. J Surg Oncol 2015; 112(5): 486-491. (doi: 10.1002/jso.24030)
6. Lam AKY. Update on paragangliomas and pheochromocytomas. Turk Patoloji Derg 2015, 31(Suppl): 105-112. (doi: 10.5146/tjpath.2015.01318)

7. Mohammed AA, El-Shentenawy AM, Sherisher MA, El-Khatib HM Target therapy in metastatic pheochromocytoma: current perspectives and controversies. Oncol Rev 2014; 8(2): 249. (doi: 10.4081/oncol.2014.249)

8. Negro A, Santi R, Giunta A, Lococo F, Gemelli G, Piana S, et al. Incidentally discovered pheochromocytoma and aldosteroneproducing adenoma in the same adrenal gland. Ital J Med 2015; 9(3): 294-298. (doi: 10.4081/itjm.2015.557)

\section{Authors:}

Vitorino Modesto dos Santos - MD, PhD, Professor of Internal Medicine, Medical Course, Catholic University, Brasília-DF, Brazil; Preceptor of Internal Medicine, Armed Forces Hospital, Brasília-DF, Brazil.

Marcos Correa da Trindade - MD, Preceptor of Oncology, Clinical Oncology Division, Armed Forces Hospital, Brasília-DF, Brazil.

Renata Faria Silva - MD, Medical Resident of Internal Medicine, Armed Forces Hospital, Brasília-DF, Brazil.

Uadson Silva Barreto - MD, Medical Resident of Internal Medicine, Armed Forces Hospital, Brasília-DF, Brazil. 